\title{
Angiogenic and inflammatory biomarkers in midpregnancy and small-for-gestational-age outcomes in Tanzania
}

\section{Citation}

Darling, Anne Marie, Chloe R. McDonald, Andrea L. Conroy, Kyla T. Hayford, W. Conrad Liles, Molin Wang, Said Aboud, Willy S. Urassa, Kevin C. Kain, and Wafaie W. Fawzi. 2014. "Angiogenic and Inflammatory Biomarkers in Midpregnancy and Small-for-Gestational-Age Outcomes in Tanzania." American Journal of Obstetrics and Gynecology 211 (5) (November): 509.e1-509.e8. doi:10.1016/j.ajog.2014.05.032.

\section{Published Version}

doi:10.1016/j.ajog.2014.05.032

\section{Permanent link}

http://nrs.harvard.edu/urn-3:HUL.InstRepos:26836021

\section{Terms of Use}

This article was downloaded from Harvard University's DASH repository, and is made available under the terms and conditions applicable to Open Access Policy Articles, as set forth at http:// nrs.harvard.edu/urn-3:HUL.InstRepos:dash.current.terms-of-use\#OAP

\section{Share Your Story}

The Harvard community has made this article openly available.

Please share how this access benefits you. Submit a story.

Accessibility 


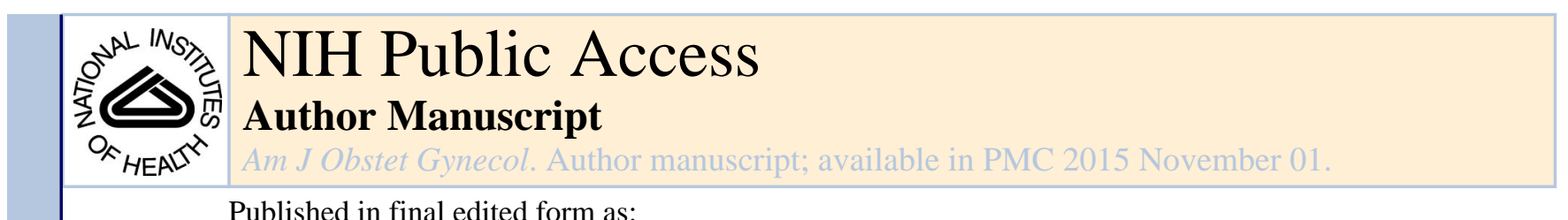

Published in final edited form as:

Am J Obstet Gynecol. 2014 November ; 211(5): 509.e1-509.e8. doi:10.1016/j.ajog.2014.05.032.

\title{
Angiogenic and inflammatory biomarkers in mid-pregnancy and small-for-gestational age outcomes in Tanzania
}

\begin{abstract}
Anne Marie DARLING, MSc, Chloe R. MCDONALD, MSc, Andrea L. CONROY, PhD, Kyla T. HAYFORD, PhD, Nimerta RAJWANS, MSc, Molin WANG, PhD, Said ABOUD, PhD, Willy S. URASSA, PhD, Kevin C. KAIN, MD, and Wafaie W. FAWZI, PhD

Department of Global Health and Population, Harvard School of Public Health, Boston, MA (Ms Darling and Dr Fawzi); SAR Laboratories, Sandra Rotman Centre for Global Health, University Health Network-Toronto General Hospital, University of Toronto, Toronto, Canada (Ms McDonald, Ms Rajwans, and Drs Conroy, Hayford, and Kain); Institute of Medical Science, University of Toronto, Toronto, Canada (Ms McDonald and Dr Kain); Department of Epidemiology, Harvard School of Public Health, Boston, MA (Drs Wang and Fawzi); Department of Microbiology and Immunology, Muhimbili University of Health and Allied Sciences, Dar es Salaam, Tanzania (Dr Aboud); Diagnostics and Laboratory Technology Team, World Health Organization, Geneva, Switzerland (Dr Urassa); Tropical Disease Unit, Division of Infectious Diseases, Department of Medicine, University of Toronto, Toronto, Canada (Dr Kain) and the Department of Nutrition, Harvard School of Public Health, Boston, MA (Dr Fawzi).
\end{abstract}

\begin{abstract}
OBJECTIVE-To investigate the relationship between a panel of angiogenic and inflammatory biomarkers measured in mid-pregnancy and small-for-gestational age (SGA) outcomes in subSaharan Africa.

STUDY DESIGN-Concentrations of 18 angiogenic and inflammatory biomarkers were determined in 432 pregnant women in Dar es Salaam, Tanzania who participated in a trial examining the effect of multivitamins on pregnancy outcomes. Infants falling below the $10^{\text {th }}$ percentile of birth weight for gestational age relative to the applied growth standards were considered SGA. Multivariate binomial regression models with the log link function were used to determine the relative risk of SGA associated with increasing quartiles of each biomarker.

Stepwise cubic restricted splines were used to test for non-linearity of these associations. Receiver operating curves obtained from multivariate logistic regression models were used to assess the discriminatory capability of selected biomarkers.
\end{abstract}

\footnotetext{
(C) 2014 Mosby, Inc. All rights reserved.

Corresponding author: Anne Marie Darling, Department of Global Health and Population, Harvard School of Public Health, 1635 Tremont St, Boston, MA 02120. adarling@hsph.harvard.edu. 617-432-1222 (work), 617-583-3109 (cell), 617-432-1355 (fax).

Publisher's Disclaimer: This is a PDF file of an unedited manuscript that has been accepted for publication. As a service to our customers we are providing this early version of the manuscript. The manuscript will undergo copyediting, typesetting, and review of the resulting proof before it is published in its final citable form. Please note that during the production process errors may be discovered which could affect the content, and all legal disclaimers that apply to the journal pertain.

The authors report no conflict of interest.
} 
RESULTS-A total of 60 participants (13.9\%) gave birth to SGA infants. Compared to those in the first quartile, the risk of SGA was reduced among those in the fourth quartiles of VEGF-A (adjusted risk ratio (RR) 0.38, 95\% Confidence Interval (CI), 0.19-0.74), PGF (adjusted RR 0.28, 95\% CI, 0.12-0.61), sFlt-1 (adjusted RR 0.48, 95\% CI, 0.23-1.01), MCP-1 (adjusted RR 0.48, 95\% CI, 0.25-0.92), and Leptin (adjusted RR 0.46, 95\% CI, 0.22-0.96)

CONCLUSION-Our findings provide evidence of altered angiogenic and inflammatory mediators, at mid-pregnancy, in women who went on to deliver small for gestational age infants.

\section{Keywords}

Angiogenesis; inflammation; small-for-gestational age

\section{INTRODUCTION}

Intrauterine growth restriction (IUGR) is a major public health problem that affects $4-8 \%$ of pregnancies in developed countries ${ }^{1}$ and an estimated $27 \%$ of pregnancies in low and middle income countries. ${ }^{2}$ The consequences of inadequate fetal growth can be life-long. Growthrestricted infants have an increased risk of morbidity and mortality during the neonatal and post-neonatal period, an increased risk of developmental delay, short stature, neurodevelopmental impairment and cerebral palsy during childhood as well as an increased risk of myriad cardiometabolic disorders during adulthood. . $^{1,2,3}$

A small number of interventions have had modest success in reducing the occurrence of smallness for gestational age (SGA) ${ }^{4}$, a commonly used surrogate outcome for IUGR. Nonetheless, considerable demand still exists for effective preventive measures. Development of these measures requires an improved understanding of the pathogenesis of IUGR and the ability to identify pregnancies at risk in early and mid-gestation. The examination of biomarkers associated with reduced fetal growth can assist in both endeavors.

Previous studies have linked a number of biomarkers to IUGR ${ }^{5}$ but few have been conducted in resource-constrained settings where the burden of IUGR is greatest. Much of this research has focused on biomarkers of angiogenesis, the branching and non-branching remodelling of the placental vasculature ${ }^{6}$ that is a crucial process for adequate perfusion of oxygen and nutrients to the fetus. Other evidence suggests that IUGR may involve a proinflammatory cytokine bias. ${ }^{7}$. For this reason, evaluating the association between inflammatory biomarkers and IUGR may be of particular relevance in developing countries, where common infections such as malaria can induce a proinflammatory microenvironment. In this study, we investigate the relationship between a range of angiogenic and inflammatory biomarkers during mid-pregnancy and intrauterine growth restriction as defined by SGA. 


\section{MATERIALS AND METHODS}

\section{Study site and participants}

We obtained data and specimens for these analyses from a randomized, double-blind, placebo-controlled trial of daily multivitamin supplementation during pregnancy. A detailed description of the trial has been published elsewhere. ${ }^{8}$ Trial participants were HIV-negative, between 12 and 27 weeks of gestation, and planning to stay in Dar es Salaam for at least 1 year after delivery. At the time of enrollment, participants were randomly assigned to receive a daily oral dose of a multivitamin containing $20 \mathrm{mg}$ of vitamin $\mathrm{B}_{1}, 20 \mathrm{mg}$ of vitamin $B_{2}, 25 \mathrm{mg}$ of vitamin $\mathrm{B}_{6}, 100 \mathrm{mg}$ of niacin, $50 \mu \mathrm{g}$ of vitamin $\mathrm{B}_{12}, 500 \mathrm{mg}$ of vitamin $\mathrm{C}$, and $20 \mathrm{mg}$ of vitamin E, or a placebo. All trial participants also received daily doses of 60 $\mathrm{mg}$ of elemental iron and $0.25 \mathrm{mg}$ of folic acid. We limited the present analyses to primigravid women, since they are at higher risk for fetal growth restriction than multigravid women. ${ }^{9}$ In addition, we limited these analyses to singleton births. Multiple gestations are associated with both alterations in angiogenic markers ${ }^{10}$ and a higher risk of adverse pregnancy outcomes ${ }^{11}$ and could therefore confound the results of the study. From among the subset of primigravid trial participants with singleton pregnancies, known birth outcomes, and stored baseline plasma samples, we randomly selected 432 participants for these analyses.

\section{Ethics Statement}

The Institutional Review Boards at the Muhimbili University of Health and Allied Sciences in Dar es Salaam and the Harvard School of Public Health in Boston granted ethical approval for the study.

\section{Exposure}

Maternal peripheral blood samples were collected in EDTA vacutainer tubes at enrolment, plasma separated, and stored at $-80^{\circ} \mathrm{C}$ prior to testing. For the present study, plasma samples underwent analysis for the following 18 angiogenic and inflammatory biomarkers: angiopoietin-1 (Ang-1), angiopoietin-2 (Ang-2), angiopoietin-like 3 (Angptl3), vascular endothelial growth factor (VEGF-A), soluble fms-like tyrosine kinase 1 (sFlt-1), soluble tumor necrosis factor receptor 2 (sTNFR2), placental growth factor (PGF), macrophage inflammatory protein-1 beta (MIP $\beta / C C L 4)$, monocyte chemoattractant protein-1 (MCP-1/ CCL2), Leptin, interleukin-1 beta (IL1 $\beta$ ), interleukin-18 binding protein (IL-18BP), soluble intercellular adhesion molecule-1 (sICAM1), Complement Factor D (Factor D), soluble endoglin (sEng), C-reactive protein (CRP), chitinase-3-like protein-1 (CHI3L1), and complement component C5a (C5a). All analyses utilized commercially available ELISAs (Duosets, R\&D Systems, Minneapolis, MN). To increase sensitivity, samples were incubated for two hours at room temperature $\left(18-28^{\circ} \mathrm{C}\right)$ for the analyses of CRP, C5a, Factor $\mathrm{D}$ and VEGF-A, and overnight at $4^{\circ} \mathrm{C}$ for the analyses of all other biomarkers. ELISA analysis was blinded to infant size for gestational age at birth. 


\section{Outcomes}

At enrollment, participants reported the date of their last menstrual period (LMP). These dates were used to calculate gestational ages. Research midwives measured birth weights of newborns to the nearest $10 \mathrm{~g}$ following delivery. We defined SGA births as those falling below the $10^{\text {th }}$ percentile of birth weight for gestational age as in the parent study. ${ }^{8}$

\section{Statistical analysis}

We tested the distributions of each biomarker for normality using the Shapiro-Wilks test. Because the distributions of each biomarker deviated from normality, we used the Wilcoxon rank-sum test to non-parametrically examine whether the levels of each biomarker differed between SGA and appropriate-for-gestational age (AGA) infants. We estimated the relative association between each biomarker and SGA by categorizing each participant's biomarker values into quartiles and using log-binomial regression to determine the risk ratios and $95 \%$ confidence intervals for SGA for participants in each of the upper 3 quartiles compared to those in the lowest quartile. In most cases, the log-binomial models failed to converge and were replaced with log-Poisson models, which provide consistent but not fully efficient estimates of the risk ratio and its confidence intervals. ${ }^{13}$ Multivariate models also contained terms for covariates that predicted SGA at an alpha level of less than 0.2 in univariate logbinomial models. These variables included literacy (yes/no), marital status (yes/no), gestational age at study entry $(<20,20-25,25-30$ weeks), and district of recruitment (Ilala/ Temeke/Kinondoni). We non-parametrically examined the possibility of non-linear relationships between continuous biomarker levels and SGA status using restricted cubic splines ${ }^{14}$ with four knots placed at the points corresponding to the $20^{\text {th }}, 40^{\text {th }}, 60^{\text {th }}$, and $80^{\text {th }}$ percentiles. For biomarkers that did not depart from linearity in relation to SGA status, we then tested for the presence of linear trends by assigning each quartile the median value and modeling this variable as a continuous variable.

Because multivitamin supplementation reduced the risk of SGA in the parent trial, ${ }^{8}$ we considered assigned treatment arm in the parent trial as a potential modifier of the relationship between each biomarker and the risk of an SGA birth. To do so, we dichotomized each biomarker at the median to create "high" and "low" categories, computed cross product terms by multiplying the dichotomous biomarker variables by the indicator variable for treatment arm, and assessed the significance of this cross-product term using a likelihood ratio test. All statistical analyses were performed using SAS 9.2 software (SAS Institute, Cary, NC).

\section{RESULTS}

Participant characteristics are presented in Table 1. At the time of enrollment into the parent trial, participants had a median age of 20.6 (IQR 18.6-22.6) and a median gestational age of 22 weeks (IQR 19.4 -24.6). The majority of participants (67.4\%) were of normal weight for height. Eleven percent of participants had a mid-upper arm circumference of $22.5 \mathrm{~cm}$ or less. Approximately one fifth of participants reported that their household spent 500 Tanzanian shillings or less (US \$0.31) per person per day on food. The majority of participants were 
able to read (90.5\%), had completed less than 8 years of schooling $(73.8 \%)$, and were married (79.2\%). Of the 432 participants, 60 (13.9\%) delivered infants that were SGA.

Table 2 displays the median values of each biomarker among SGA and AGA deliveries. Compared to women who gave birth to AGA infants, women who gave birth to SGA infants had notably lower median levels of VEGF-A $(9.43 \mathrm{pg} / \mathrm{ml}$ (interquartile range (IQR) 7.81, $85.38)$ vs. $51.08 \mathrm{pg} / \mathrm{ml}$ (IQR 7.81, 363.54)), sFlt-1 (0.94 ng/ml (IQR 0.23, 2.38) vs. 1.31 $\mathrm{ng} / \mathrm{ml}$ (IQR 0.55, 4.11)), PGF (1.18 ng/ml (IQR 0.65, 1.98) vs. $1.61 \mathrm{ng} / \mathrm{ml}$ (IQR 0.91, 2.84)), MCP-1/CCL2 (20.91 pg/ml (IQR 7.81, 187.09) vs. $48.14 \mathrm{pg} / \mathrm{ml}(11.56,247.91)$ ), and Leptin (7.74 ng/ml (IQR 4.76, 12.88) vs. 6.36 (IQR 4.04, 10.42)), and notably higher levels of sICAM-1 (184.53 ng/ml (IQR 120.93, 241.80) vs. $157.68 \mathrm{ng} / \mathrm{ml}$ (95\% CI 109.40, 237.01)).

Since the biomarkers examined have unique profiles with respect to gestational age, we examined biomarker levels according to the gestational age at which the plasma sample was collected. Median levels of VEGF-A and sFlt-1 were consistently lower in the SGA group compared to the AGA group among women who were between 12-16 weeks of gestation, 17-21 weeks of gestation, and 22-27 weeks of gestation (Figure 1a,b). Median levels of PGF and MCP-1/CCL2 were higher in the SGA group compared to the AGA group among women who were between 12-16 weeks of gestation, but lower among women who were between 17-21 weeks of gestation and 22-27 weeks of gestation (Figure 1c,d). The lower median levels of Leptin in the SGA group were only apparent among women who were 22-27 weeks of gestation, and the higher median levels of sICAM-1 were observed only among women who were 17-21 weeks of gestation (Figure 1e,f).

Table 3 shows the relative risks for an SGA delivery according to quartiles of biomarker values. Women with VEGF-A levels in the third and fourth quartiles had a significantly reduced risk of giving birth to an SGA infant compared to women in the first quartile, but this reduction was more pronounced in the third quartile (multivariate risk ratio $0.24 ; 95 \%$ $\mathrm{CI}(0.11,0.53))$ than in the fourth quartile (multivariate risk ratio 0.38 ; (95\% CI $0.19,0.74)$ ). Spline analysis confirmed a significant non-linear relationship $(\mathrm{p}=0.001)$ between VEGF-A and SGA status that appeared L-shaped, with a relatively constant reduction in the odds of SGA observed at concentrations of approximately $100 \mathrm{pg} / \mathrm{ml}$ and above (Figure 2). Women with plasma PGF in the highest quartile had a statistically significant reduced risk of delivering an SGA infant (72\%; 95\% CI 59\%, 88\%) compared to those in the lowest quartile. Similar to the results for VEGF-A, spline analysis showed that PGF had a significant non-linear relationship to SGA $(\mathrm{p}=0.008)$ that showed an L-shape (Figure 3). At PGF concentrations of approximately $4 \mathrm{ng} / \mathrm{ml}$ and above, the reduction in odds associated with each increasing $\mathrm{ng} / \mathrm{ml}$ of PGF seemed to remain relatively constant.

We also observed associations between Leptin, sFlt-1, MCP-1/CCL2, and sICAM-1 and SGA status. Compared to women in the first quartile, women with plasma Leptin in the fourth quartile had a 54\% (95\% CI 4\%, 78\%) reduced risk of SGA. sFlt-1 in the highest quartile was associate with a reduced risk of delivering an SGA infant that approached statistical significance (multivariate risk ratio $0.48 ; 95 \%$ CI $0.23,1.01$ ). Across increasing quartiles of MCP-1/CCL2, the risk of SGA decreased by $56 \%$ (95\% CI 13\%, 77\%), $47 \%$ $(95 \%$ CI $2 \%, 71 \%)$, and $52 \%(95 \%$ CI $8 \%, 75 \%)$ respectively. Though the relative risks for 
the upper quartiles of sICAM-1 were not associated with SGA risk, spline analysis suggested a non-linear relationship between sICAM-1 and SGA ( $p=0.02)$. Treatment assignment in the parent trial did not significantly modify the associations between any of the other biomarkers and SGA.

\section{COMMENT}

We found that higher plasma levels of the pro-angiogenic markers VEGF-A, PGF, and the anti-angiogenic marker sFlt-1 at mid-pregnancy were associated with a reduced risk of giving birth to an SGA infant. The L-shape of these associations implies that reaching critical thresholds of these proteins may be necessary for adequate fetal growth. Based on our data, these thresholds appear to exist around $100 \mathrm{pg} / \mathrm{ml}$ for VEGF-A and $4 \mathrm{ng} / \mathrm{ml}$ for PGF. In addition, higher levels of the inflammatory protein, MCP-1 and the adipocytokine hormone, Leptin were also associated with a reduced risk of delivering an SGA infant.

VEGF-A, PGF, and s-Flt all belong to the vascular endothelial growth factor (VEGF) family of structurally similar proteins which are essential for placental vascular development. VEGF-A is necessary for vasculogenesis, ${ }^{6}$ the formation of the blood vessels from a previously avascular area, which occurs primarily in the first trimester. In the second and third trimester, both VEGFA and PGF regulate angiogenesis, the elongation, branching and vascular remodelling critical to support rapid fetal growth in late pregnancy. ${ }^{15}$ Our findings suggest that dysregulated levels of pro-and anti-angiogenic factors at mid-pregnancy are associated with SGA outcomes. There results add to a growing body of evidence implicating altered levels of VEGF-A, PGF and s-Flt-1 in placental insufficiency and fetal growth restriction. ${ }^{16-23}$

sFlt-1 is an alternatively spliced variant of VEGFR1 that has an inhibitory effect on VEGFA and PGF signalling. ${ }^{24}$ During pregnancy, trophoblast cells secrete large amounts of soluble receptors that modulate the levels of bioavailable VEGF-A and PGF. ${ }^{25}$ In this study higher levels of levels of sFlt-1 were associated with a reduced risk of risk of SGA, in contrast to others showing either no association, ${ }^{17,} 26-28$ or a negative association between sFlt-1 and fetal growth. ${ }^{16,29-32}$ Asvold et al. ${ }^{23}$ observed that low levels of sFlt-1 in early pregnancy were associated with an increased risk of SGA, which they postulate reflects low angiogenic activity overall during this period. We studied sFlt-1 levels somewhat later in pregnancy, at which time decreases in sFlt-1 may reflect a compensatory response to the already low VEGF. The dramatically lower median levels of VEGF-A among the SGA group that were visible even among women who were only 12-16 weeks gestation (Figure 1a) may support this explanation.

MCP-1 is a chemokine that attracts and activates monocytes and macrophages to sites of inflammation. MCP-1/CCL2 has also been implicated in mediating angiogenesis in vitro and in vivo in a mouse model ${ }^{33,34}$ and in the regulation of trophoblast invasion into the placental bed. ${ }^{35}$ Our finding that women with the highest MCP-1 levels had the lowest risk of a SGA birth is in accordance with a previous observation by Georgiou et al. ${ }^{36}$, that mothers of SGA infants had significantly lower concentrations of MCP-1 at 7-10 weeks of gestation. While we also observed lower median levels of MCP-1 overall among mothers of 
SGA infants, our results contrastingly showed higher median MCP-1 levels among those whose specimens were tested between 12-16 weeks (Figure 1). Briana et al. ${ }^{37}$ found lower postnatal concentrations of MCP-1 among SGA infants and their mothers, though one cannot infer the temporality of the association from their study. Further research into MCP-1 may help to clarify the role of this chemokine in the pathobiology of fetal growth restriction.

The adipocytokine hormone Leptin takes part in the regulation of energy balance, metabolism, the immune response, and T-cell activation. During pregnancy, Leptin is synthesized by the placenta and contributes to placental growth, nutrient transfer, angiogenesis, and trophoblast invasion. ${ }^{38}$ As reviewed by Briana et al., previous studies have reported contradictory findings related to Leptin and fetal growth restriction. ${ }^{38}$ Some studies have found associations between increased Leptin levels and IUGR. A proposed explanation for these findings is that Leptin secretion from trophoblast cells increases under hypoxic conditions, ${ }^{39}$ which can be characteristic of IUGR. Conversely, other studies have observed associations between reduced plasma Leptin levels and IUGR comparable to the results we we report here. These latter studies may indicate that under some circumstances, the placenta fails to increase Leptin secretion in response to reduced placental perfusion. ${ }^{38}$ Collectively, these data suggest that some degree of leptin dysregulation has adverse consequences for fetal growth.

Strengths of this study include its prospective design, comprehensive assessment of angiogenic and inflammatory biomarkers, and ability to control for wide range of covariates as potential confounders. Although the examination of numerous biomarkers increases the potential for type I error through multiple testing, we maintained an alpha level of 0.05 for each test. Applying a Bonferroni correction to these results would have reduced the alpha level to $0.003(0.05 / 18)$. The use of such a conservative alpha level would likely inflate the probability of type II error. ${ }^{40}$ As the goal of this discovery analysis was to identify biomarkers for further investigation in relation to SGA, we did not wish to dismiss any associations of interest. Furthermore, we selected biomarkers for inclusion in the study based on a priori hypotheses about their role in the pathogenesis of fetal growth restriction.

Our study may be limited by the use of SGA as the outcome, which is defined as being below the $10^{\text {th }}$ percentile of birth weight for gestational age, since it is not entirely analogous to IUGR. ${ }^{41}$ The formal definition of IUGR refers to the failure of an infant to reach its genetic growth potential ${ }^{40}$ and is typically ascertained through ultrasound technology unavailable in this setting. Therefore, we may have misclassified some constitutionally small but healthy infants as SGA. Any misclassification of this sort would have occurred non-differentially and led to conservative relative risk estimates. In addition, some misclassification of LMP-based gestational ages may have occurred due to recall error, but any such errors would have also occurred independently of exposure status and likewise attenuated the results.

In summary, lower maternal levels of VEGF-A, PGF, MCP-1, and Leptin appear to precede SGA in this study cohort. Given the importance of each of these factors in placental vascular development, our findings support the hypothesis that alterations in levels of critical mediators of angiogenesis at mid-pregnancy contribute to the development of placental 
vascular insufficiency, whereby the placenta cannot meet the metabolic demands of the growing fetus resulting in SGA outcomes. Although these findings are exploratory, they compel further investigation into the role of altered of angiogenesis in the pathobiology of SGA as well as the use of these markers as potential early diagnostic tools or targets for interventions to reduce SGA.

\section{Acknowledgments}

We thank the mothers and children, the field teams, including nurses, midwives, supervisors, and laboratory staff, and the administrative staff who made the study possible.

This work was supported in part by the Global Alliance to Prevent Prematurity and Stillbirth (GAPPS) and the Bill and Melinda Gates Foundation Grand Challenges in Global Health: Preventing Preterm Birth Initiative Grant No. 12003 [KCK]; the Canadian Institutes of Health Research (CIHR) MOP-115160 and 13721 [KCK], a Canada Research Chair in Molecular Parasitology [KCK], a CIHR Doctoral Research Award [CRM], and the National Institute of Child Health and Human Development (NICHD) R01 37701 [WF].

\section{REFERENCES}

1. Lee, Anne CC.; Katz, Joanne; Blencowe, Hannah, et al. National and regional estimates of term and preterm babies born small for gestational age in 138 low-income and middle-income countries in 2010. The Lancet Global Health. 2013; 1:e26-36. [PubMed: 25103583]

2. Katz, Joanne; Lee, Anne CC.; Kozuki, Naoko, et al. Mortality risk in preterm and small-for gestational-age infants in low-income and middle-income countries: a pooled country analysis. The Lancet. 2013; 382:60993-9.

3. Longo S, Bollani L, Decembrino L, Di Comite A, Angelini M, Stronati M. Short-term and longterm sequelae in intrauterine growth retardation (IUGR). J Matern Fetal Neonatal Med. 2013; 26:222-5. [PubMed: 23030765]

4. Morris RK, Oliver EA, Malin G, Khan KS, Meads C. Effectiveness of interventions for the prevention of small-for-gestational age fetuses and perinatal mortality: a review of systematic reviews. Acta Obstet Gynecol Scand. 2013; 92:143-51. [PubMed: 23066728]

5. Conde-Agudelo A, Papageorghiou AT, Kennedy SH, Villar J. Novel biomarkers for predicting intrauterine growth restriction: a systematic review and meta-analysis. BJOG. 2013; 120:681-94. [PubMed: 23398929]

6. Kaufmann P, Mayhew TM, Charnock-Jones DS. Aspects of human fetoplacental vasculogenesis and angiogenesis. II. Changes during normal pregnancy. Placenta. 2004; 25:114-26. [PubMed: 14972444]

7. Raghupathy R, Al-Azemi M, Azizieh F. Intrauterine growth restriction: cytokine profiles of trophoblast antigen-stimulated maternal lymphocytes. Clin Dev Immunol. 2012; 2012:734865. [PubMed: 22110537]

8. Fawzi WW, Msamanga GI, Urassa W, et al. Vitamins and perinatal outcomes among HIV-negative women in Tanzania. N Engl J Med. 2007; 356:1423-31. [PubMed: 17409323]

9. Watson-Jones D, Weiss HA, Changalucha JM, Todd J, Gumodoka B, Bulmer J, Balira R, Ross D, Mugeye K, Hayes R, Mabey D. Adverse birth outcomes in United Republic of Tanzania--impact and prevention of maternal risk factors. Bull World Health Organ. 2007; 85:9-18. [PubMed: 17242753]

10. Maynard SE, Moore Simas TA, Solitro MJ, Rajan A, Crawford S, Soderland P, Meyer BA. Circulating angiogenic factors in singleton vs multiple-gestation pregnancies. Am J Obstet Gynecol. 2008; 198:200, e1-7. [PubMed: 18226624]

11. Berkowitz, RL. Multiple gestations.. In: Gabbe, SG.; Niebyl, JR.; Simpson, JL., editors. Obstetrics: normal and problem pregnancies. Churchill Livingstone; New York: 1986. p. 739-67.

12. Brenner WE, Edelman DA, Hendricks CH. A standard of fetal growth for the United States of America. Am J Obstet Gynecol. 1976; 126:555-64. [PubMed: 984126] 
13. Spiegelman D, Hertzmark E. Easy SAS calculations for risk or prevalence ratios and differences. Am J Epidemiol. 2005; 162:199-200. [PubMed: 15987728]

14. Durrleman S, Simon R. Flexible regression models with cubic splines. Stat Med. 1989; 8:551-61. [PubMed: 2657958]

15. Geva E, Ginzinger DG, Zaloudek CJ, Moore DH, Byrne A, Jaffe RB. Human placental vascular development: vasculogenic and angiogenic (branching and nonbranching) transformation is regulated by vascular endothelial growth factor-A, angiopoietin-1, and angiopoietin-2. J Clin Endocrinol Metab. 2002; 87:4213-24. [PubMed: 12213874]

16. Crispi F, Dominguez C, Llurba E, Martin-Gallan P, Cabero L, Gratacos E. Placental angiogenic growth factors and uterine artery Doppler findings for characterization of different subsets in preeclampsia and in isolated intrauterine growth restriction. Am J Obstet Gynecol. 2006; 195:2017. [PubMed: 16545329]

17. Poon LC, Zaragoza E, Akolekar R, Anagnostopoulos E, Nicolaides KH. Maternal serum placental growth factor (PIGF) in small for gestational age pregnancy at 11(+0) to 13(+6) weeks of gestation. Prenat Diagn. 2008; 28:1110-5. [PubMed: 19003787]

18. Taylor RN, Grimwood J, Taylor RS, McMaster MT, Fisher SJ, North RA. Longitudinal serum concentrations of placental growth factor: evidence for abnormal placental angiogenesis in pathologic pregnancies. Am J Obstet Gynecol. 2003; 188:177-82. [PubMed: 12548214]

19. Romero R, Nien JK, Espinoza J, et al. A longitudinal study of angiogenic (placental growth factor) and anti-angiogenic (soluble endoglin and soluble vascular endothelial growth factor receptor-1) factors in normal pregnancy and patients destined to develop preeclampsia and deliver a small for gestational age neonate. J Matern Fetal Neonatal Med. 2008; 21:9-23. [PubMed: 18175241]

20. Cowans NJ, Stamatopoulou A, Matwejew E, von Kaisenberg CS, Spencer K. First-trimester placental growth factor as a marker for hypertensive disorders and SGA. Prenat Diagn. 2010; 30:565-70. [PubMed: 20509158]

21. Benton SJ, Hu Y, Xie F, et al. Can placental growth factor in maternal circulation identify fetuses with placental intrauterine growth restriction? Am J Obstet Gynecol. 2012; 206:163, e1-7. [PubMed: 22055338]

22. Bersinger NA, Ødegard RA. Serum levels of macrophage colony stimulating, vascular endothelial, and placenta growth factor in relation to later clinical onset of pre-eclampsia and a small-for gestational age birth. Am J Reprod Immunol. 2005; 54:77-83. [PubMed: 16105099]

23. Åsvold BO, Vatten LJ, Romundstad PR, Jenum PA, Karumanchi SA, Eskild A. Angiogenic factors in maternal circulation and the risk of severe fetal growth restriction. Am J Epidemiol. 2011; 173:630-9. [PubMed: 21317220]

24. Kendall RL, Wang G, Thomas KA. Identification of a natural soluble form of the vascular endothelial growth factor receptor, FLT-1, and its heterodimerization with KDR. Biochem Biophys Res Commun. 1996; 226:324-8. [PubMed: 8806634]

25. Burton GJ, Charnock-Jones DS, Jauniaux E. Regulation of vascular growth and function in the human placenta. Reproduction. 2009; 138:895-902. [PubMed: 19470597]

26. Shibata E, Rajakumar A, Powers RW, et al. Soluble fms-like tyrosine kinase 1 is increased in preeclampsia but not in normotensive pregnancies with small-for-gestational-age neonates: relationship to circulating placental growth factor. J Clin Endocrinol Metab. 2005; 90:4895-903. [PubMed: 15886253]

27. Wathén KA, Tuutti E, Stenman UH, Alfthan H, Halmesmäki E, Finne P, Ylikorkala O, Vuorela P. Maternal serum-soluble vascular endothelial growth factor receptor-1 in early pregnancy ending in preeclampsia or intrauterine growth retardation. J Clin Endocrinol Metab. 2006; 91:180-4. [PubMed: 16263826]

28. Rajakumar A, Jeyabalan A, Markovic N, Ness R, Gilmour C, Conrad KP. Placental HIF-1 alpha, HIF-2 alpha, membrane and soluble VEGF receptor-1 proteins are not increased in normotensive pregnancies complicated by late-onset intrauterine growth restriction. Am J Physiol Regul Integr Comp Physiol. 2007; 293:R766-74. [PubMed: 17507435]

29. Chaiworapongsa T, Espinoza J, Gotsch F, et al. The maternal plasma soluble vascular endothelial growth factor receptor-1 concentration is elevated in SGA and the magnitude of the increase 
relates to Doppler abnormalities in the maternal and fetal circulation. J Matern Fetal Neonatal Med. 2008; 21:25-40. [PubMed: 18175242]

30. Stepan H, Krämer T, Faber R. Maternal plasma concentrations of soluble endoglin in pregnancies with intrauterine growth restriction. J Clin Endocrinol Metab. 2007; 92:2831-4. [PubMed: 17426082]

31. Boutsikou T, Malamitsi-Puchner A, Economou E, Boutsikou M, Puchner KP, Hassiakos D. Soluble vascular endothelial growth factor receptor-1 in intrauterine growth restricted fetuses and neonates. Early Hum Dev. 2006; 82:235-9. [PubMed: 16337100]

32. Wallner W, Sengenberger R, Strick R, et al. Angiogenic growth factors in maternal and fetal serum in pregnancies complicated by intrauterine growth restriction. Clin Sci. 2007; 112:51-7. [PubMed: 16928195]

33. Kim MY, Byeon CW, Hong KH, Han KH, Jeong S. Inhibition of the angiogenesis by the MCP-1 (monocyte chemoattractant protein-1) binding peptide. FEBS Letters. 2005; 579:1597-1601. [PubMed: 15757647]

34. Salcedo R, Ponce ML, Young HA, et al. Human endothelial cells express CCR2 and respond to MCP-1: direct role of MCP-1 in angiogenesis and tumor progression. Blood. 2000; 96:34-40. [PubMed: 10891427]

35. Naruse K, Innes BA, Bulmer JN, Robson SC, Searle RF, Lash GE. Secretion of cytokines by villous cytotrophoblast and extravillous trophoblast in the first trimester of human pregnancy. $\mathrm{J}$ Reprod Immunol. 2010; 86:148-50. [PubMed: 20888997]

36. Georgiou HM, Thio YS, Russell C, et al. Association between maternal serum cytokine profiles at 7-10 weeks' gestation and birthweight in small for gestational age infants. Am J Obstet Gynecol. 2011; 204:415, e1-415, e12. [PubMed: 21292229]

37. Briana DD, Boutsikou M, Baka S, Papadopoulos G, Gourgiotis D, Puchner KP, Hassiakos D, Malamitsi-Puchner A. Perinatal plasma monocyte chemotactic protein-1 concentrations in intrauterine growth restriction. Mediators Inflamm. 2007; 2007:65032. [PubMed: 18274642]

38. Briana DD, Malamitsi-Puchner A. Reviews: adipocytokines in normal and complicated pregnancies. Reprod Sci. 2009; 16:921-37. [PubMed: 19474287]

39. Mise H, Sagawa N, Matsumoto T, et al. Augmented placental production of leptin in preeclampsia: possible involvement of placental hypoxia. J Clin Endocrinol Metab. 1998; 83:3225-9. [PubMed: 9745432]

40. Rothman KJ. No adjustments are needed for multiple comparisons. Epidemiology. 1990; 1:43-6. [PubMed: 2081237]

41. Goldenberg RL, Cliver SP. Small for gestational age and intrauterine growth restriction: definitions and standards. Clin Obstet Gynecol. 1997; 40:704-14. [PubMed: 9429784] 
DARLING et al.
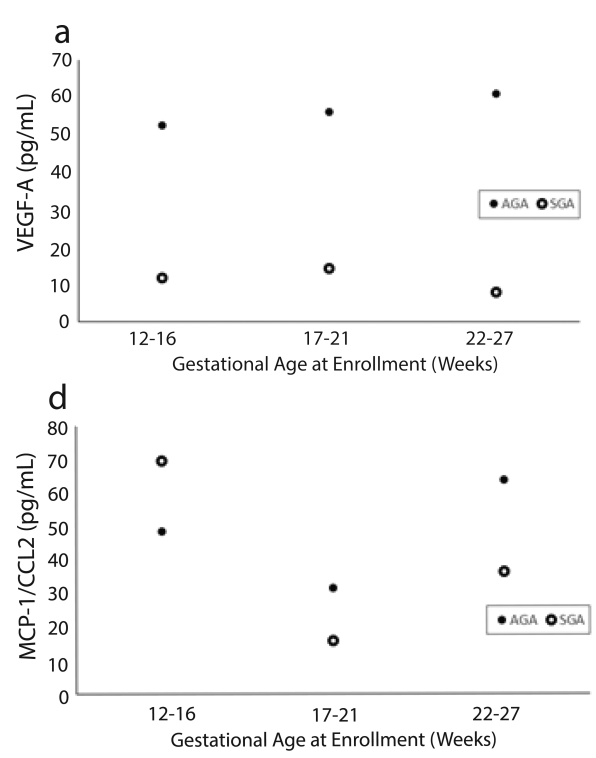
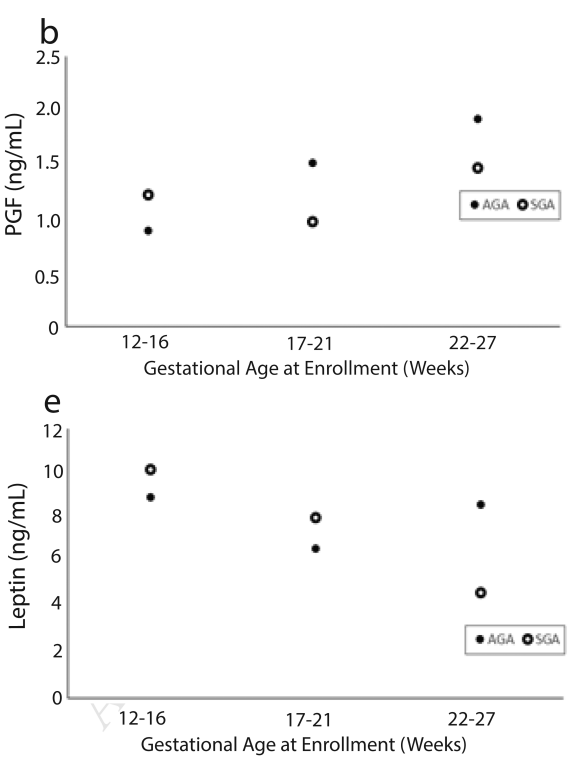

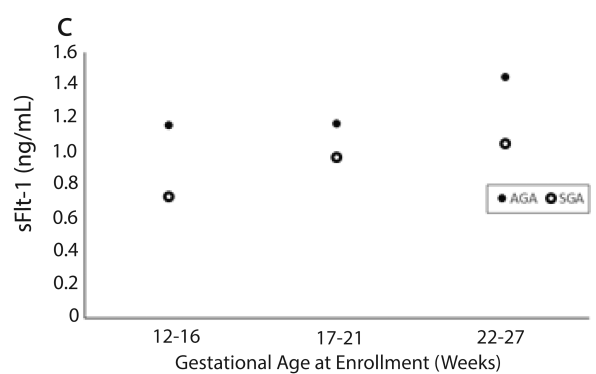

Page 11

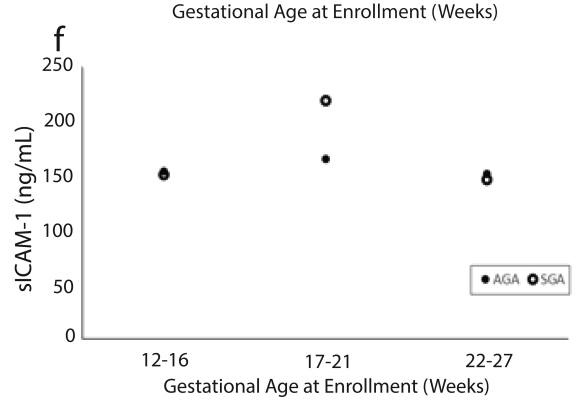

Figure 1. Median levels of selected biomarkers according to gestational age at sample collection a) VEGF-A, B) PGF, C) sFlt-1, D) MCP-1/CCL2, E) Leptin, F) sICAM-1 


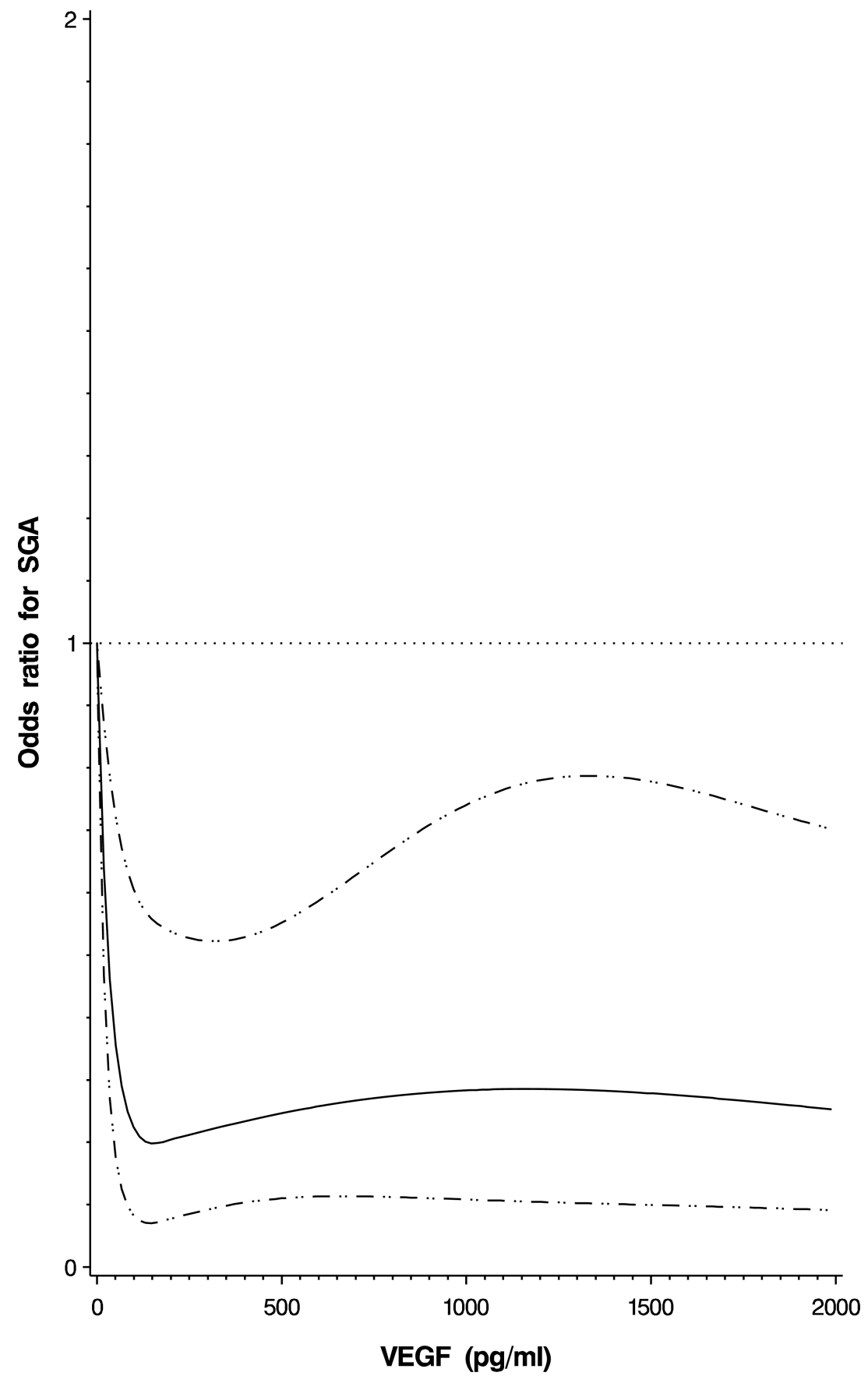

Figure 2. Non-linear relation $(\mathrm{p}=0.001)$ between mid-pregnancy VEGF levels and $(\mathrm{pg} / \mathrm{ml})$ and SGA

Adjusted for literacy (yes/no), marital status (yes/no), gestational age at study entry $(<20$, 20-25, 25-30 weeks), and district of recruitment (Ilala/Temeke/Kinondoni). Because VEGF levels were non-normally distributed, only those between the $5^{\text {th }}$ and $95^{\text {th }}$ percentile are displayed. The solid line shows the estimated odds ratio for mortality for each increasing $\mathrm{pg} / \mathrm{ml}$ of VEGF compared to the reference value of 0.03 . The horizontal line represents the null OR of 1.0. Dashed lines signify the upper and lower bounds of the 95\% CI for the OR. 


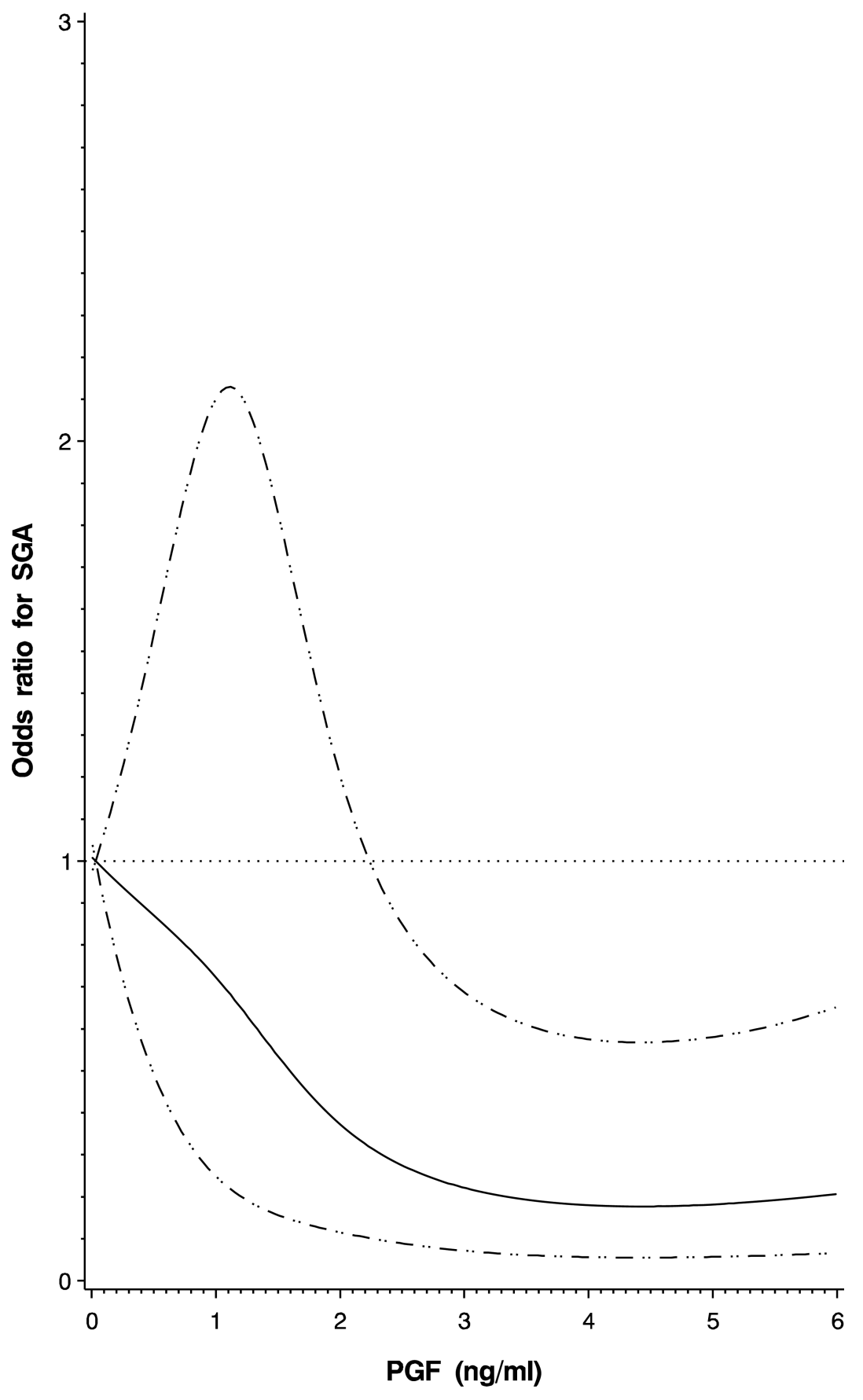

Figure 3. Non-linear relation ( $(\mathrm{p}=\mathbf{0 . 0 0 8})$ between mid-pregnancy PGF levels and $(\mathrm{pg} / \mathrm{ml})$ and SGA Adjusted for literacy (yes/no), marital status (yes/no), gestational age at study entry $(<20$, 20-25, 25-30 weeks), and district of recruitment (Ilala/Temeke/Kinondoni). Because VEGF levels were non-normally distributed, only those between the $5^{\text {th }}$ and $95^{\text {th }}$ percentile are displayed. The solid line shows the estimated odds ratio for mortality for each increasing $\mathrm{pg} / \mathrm{ml}$ of VEGF compared to the reference value of 74.07. The horizontal line represents the null OR of 1.0. Dashed lines signify the upper and lower bounds of the 95\% CI for the OR. 


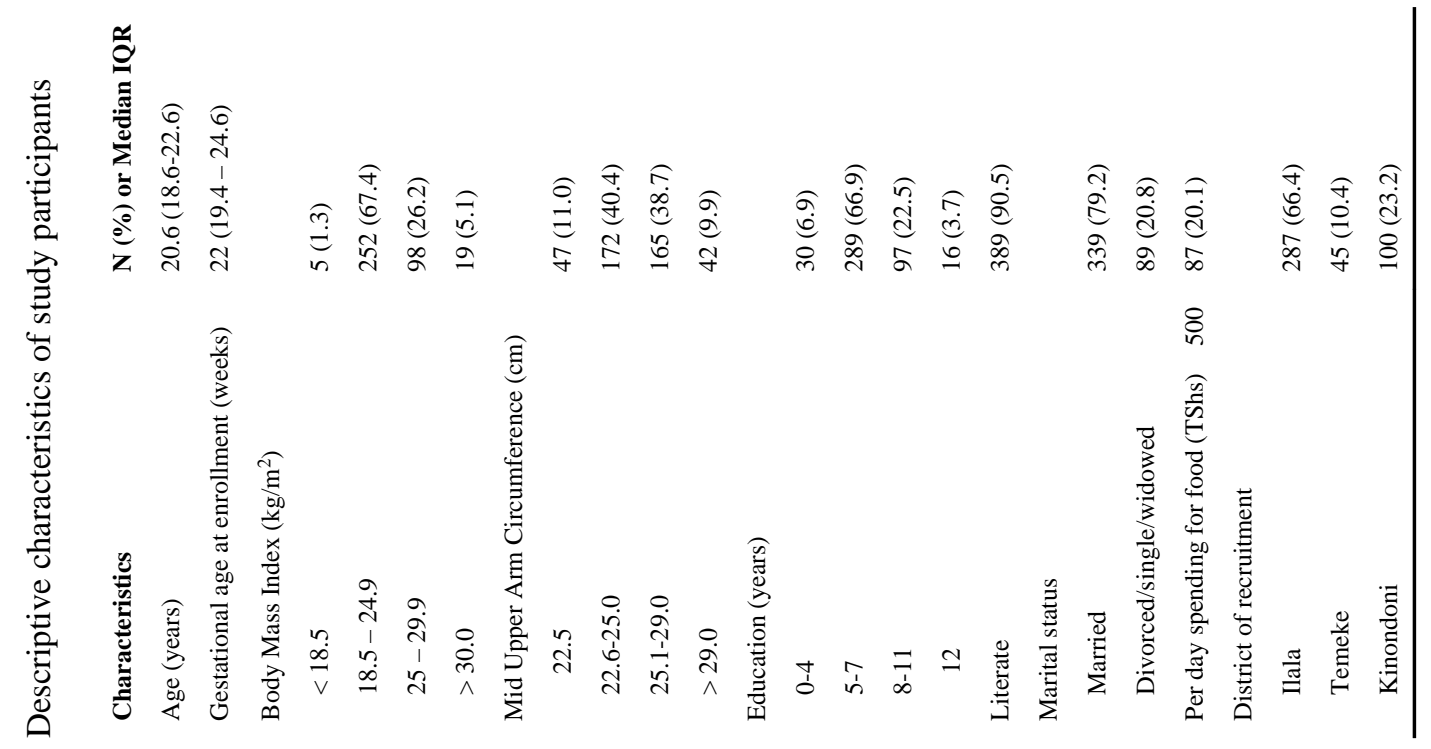




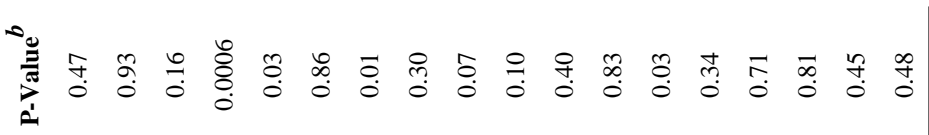

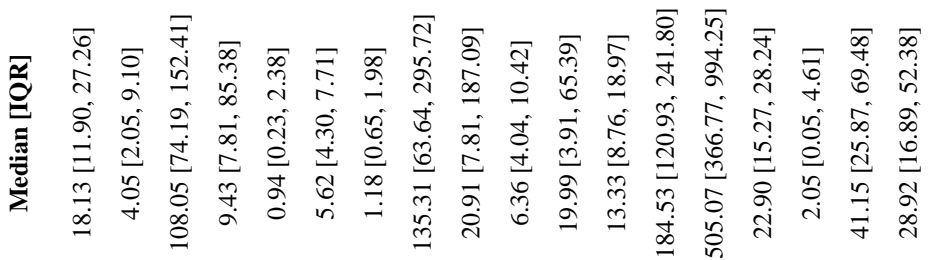

这

$$
=888888 \text { in in } 88888 \text { in } 8 \text { in } 8 \text { in }
$$

$\frac{\mathfrak{0}}{\frac{0}{0}}$

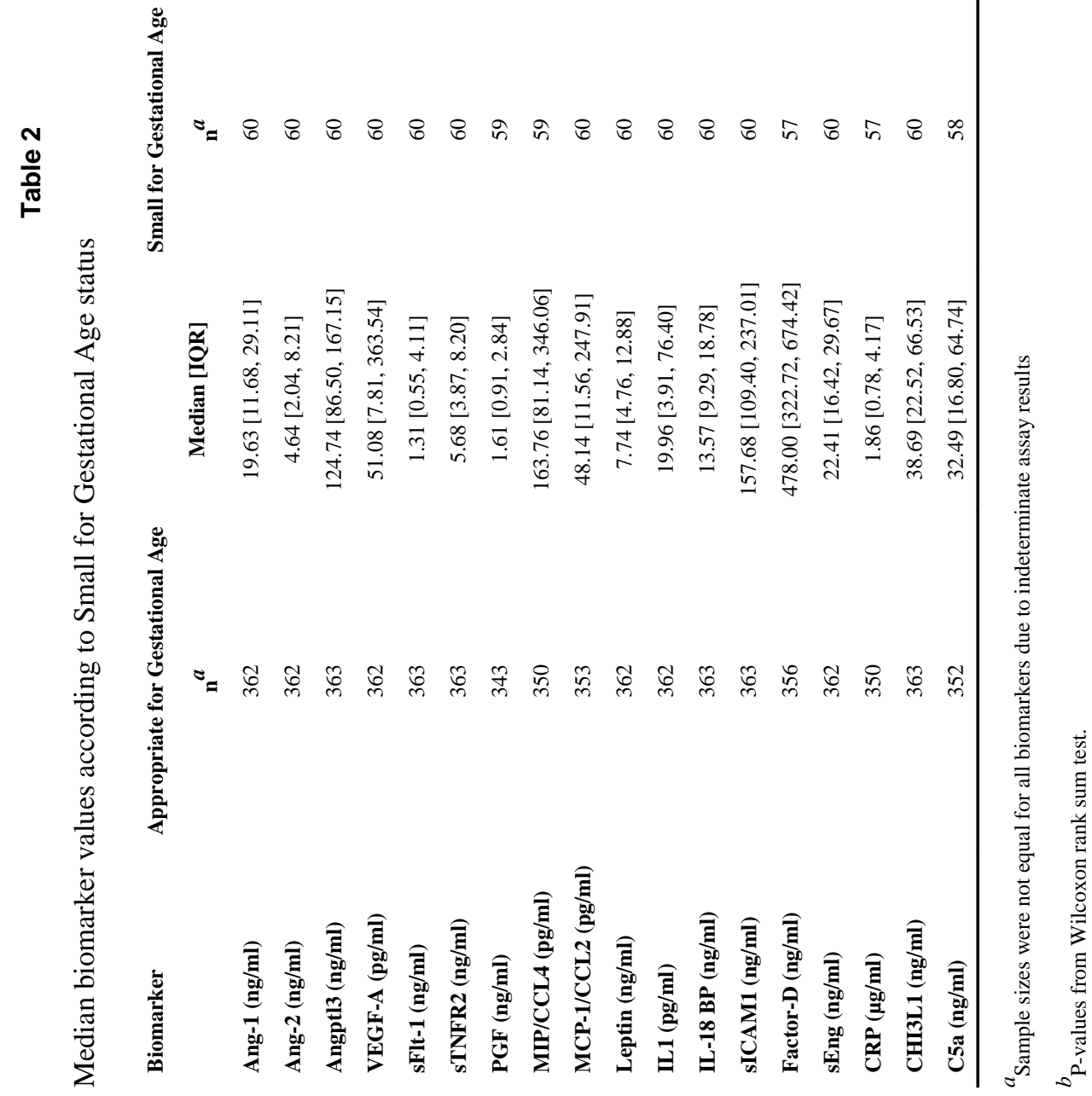




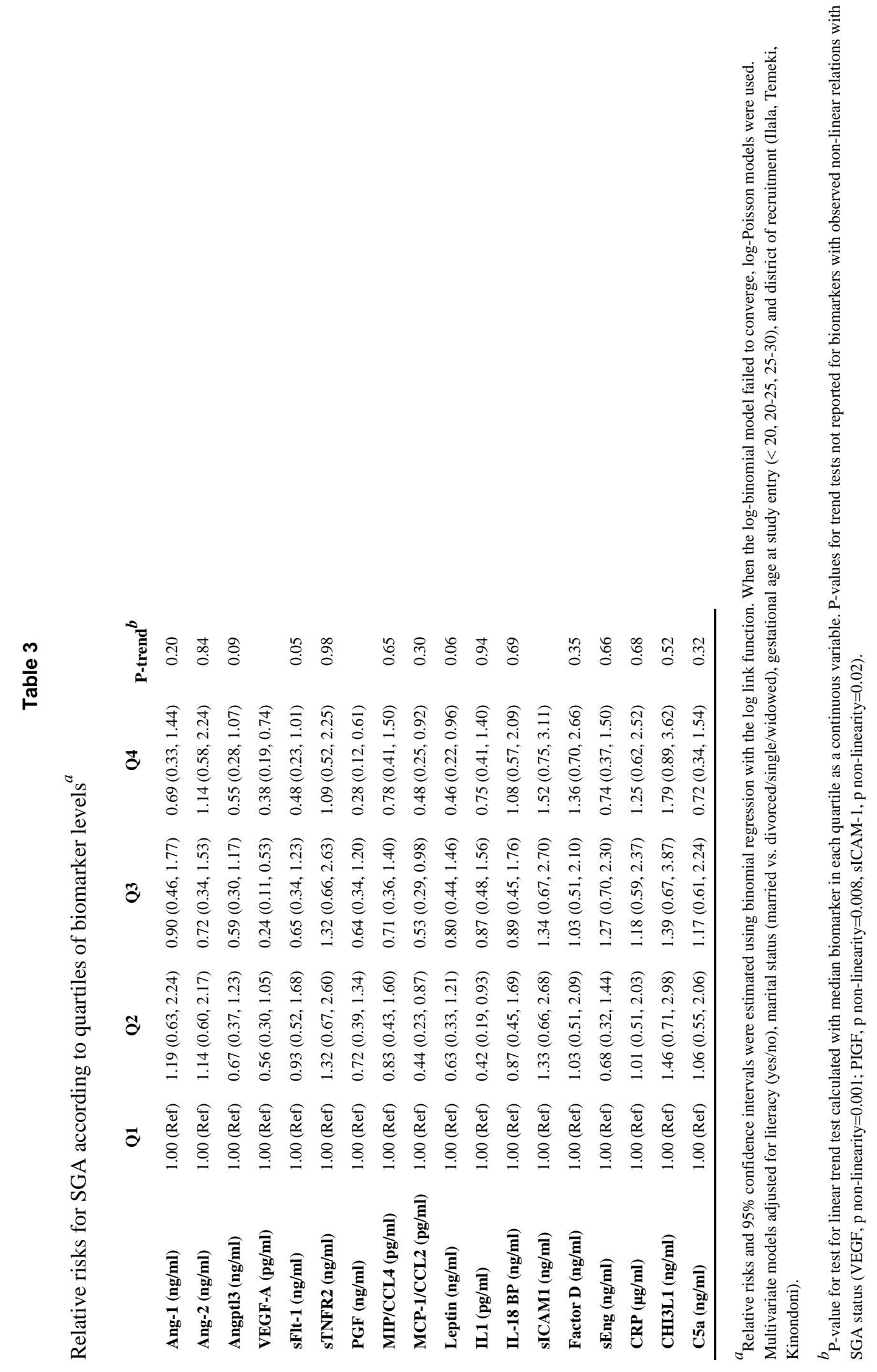

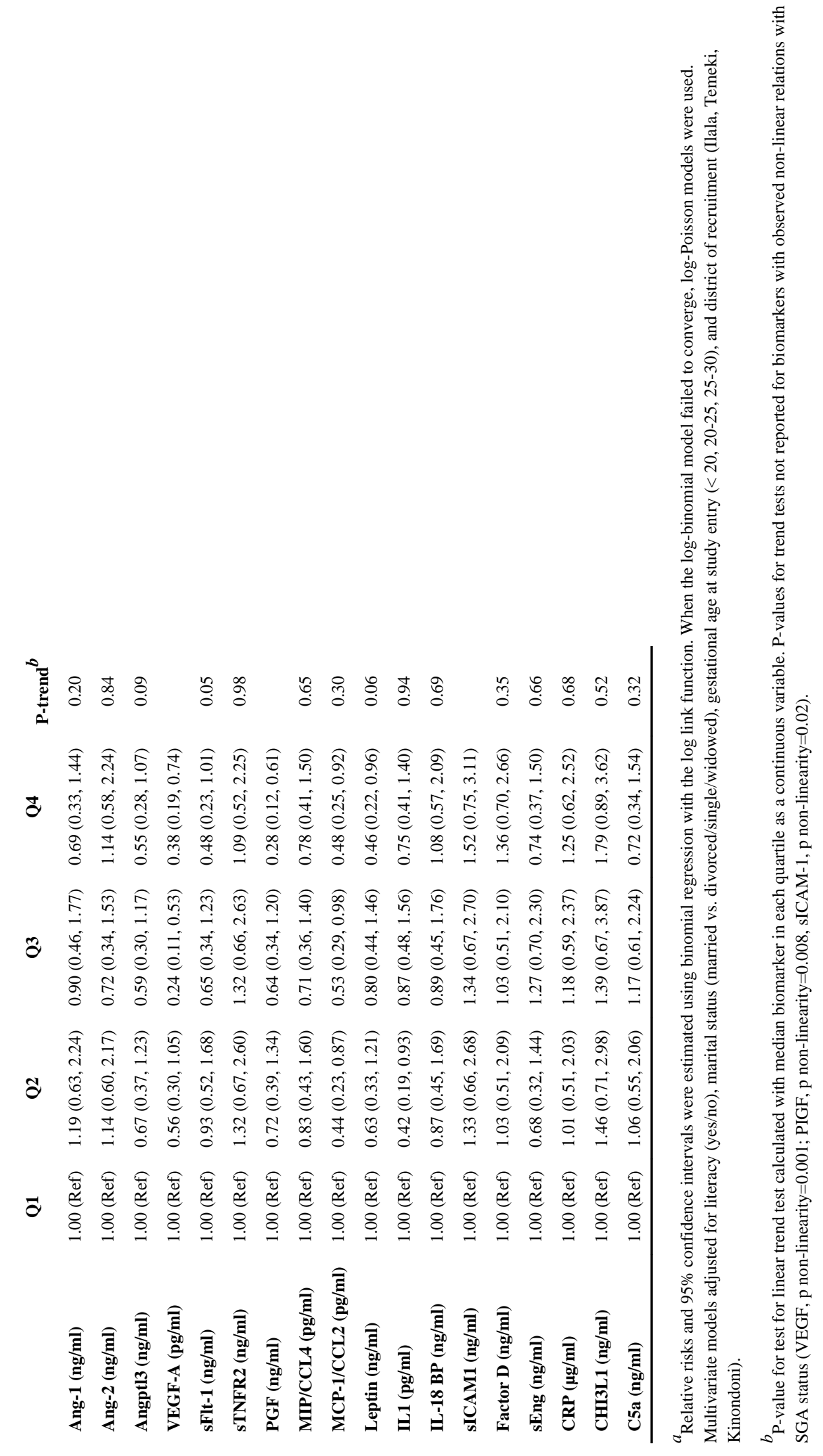

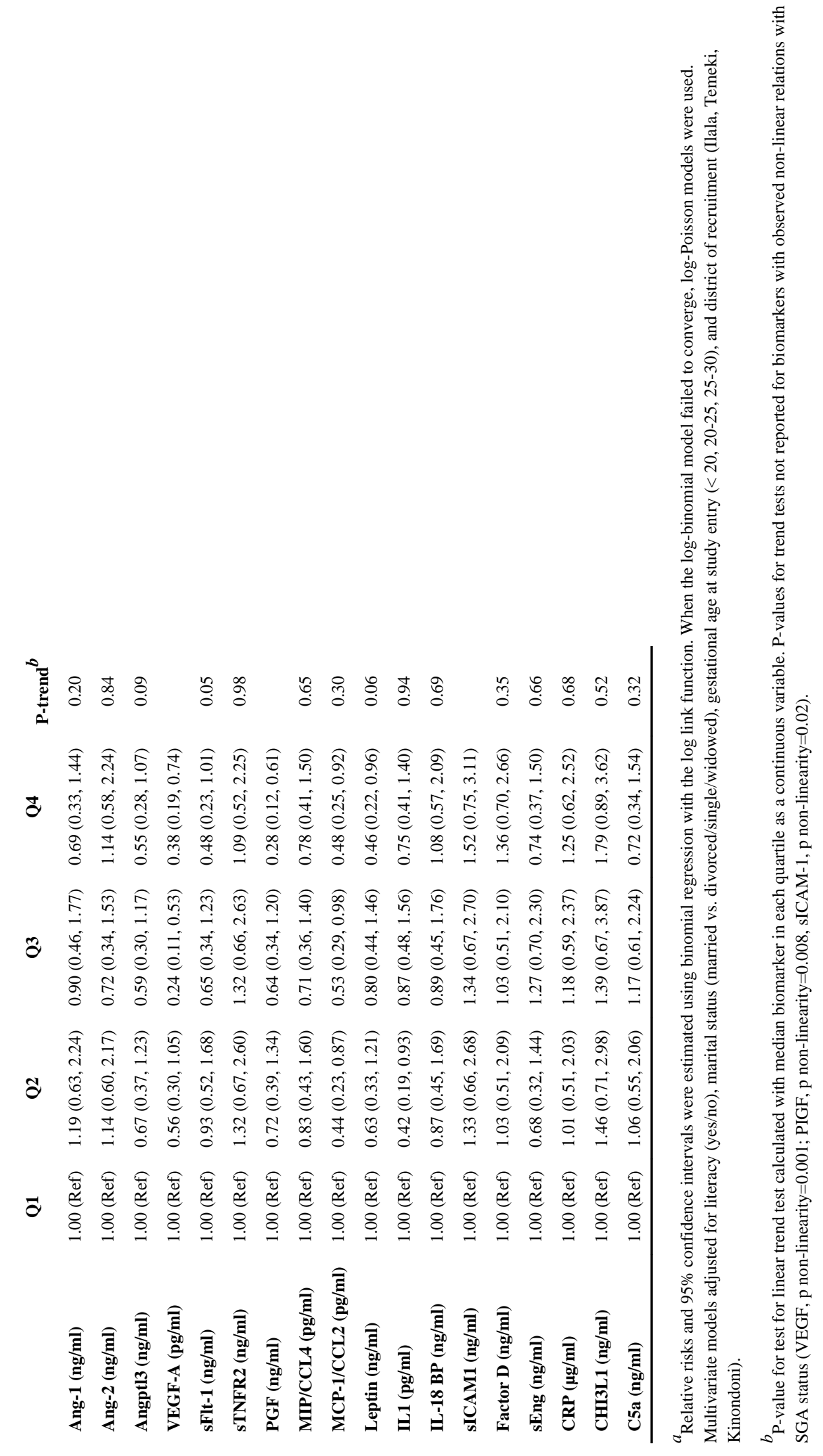

